\title{
Biomimetic systems and design in the 3D characterization of the complex vascular system of bamboo node based on X-ray microtomography and finite element analysis
}

\author{
Felipe Luis Palombinil,a) (D), Fernanda Mayara Nogueira ${ }^{2}$, Willson Kindlein Junior ${ }^{3}$, \\ Sidnei Paciornilk ${ }^{4}$, Jorge Ermesto de Araujo Mariath ${ }^{5}$, Branca Freitas de Oliveira ${ }^{6}$ \\ ${ }^{1}$ Graduate Program in Design-PGDesign, Federal University of Rio Grande do Sul-UFRGS, Porto Alegre, RS 90035-190, Brazil \\ ${ }^{2}$ Laboratory of Plant Anatomy-LAVeg, Department of Botany-UFRGS, Institute of Biosciences, Porto Alegre, RS 91540-000, Brazil; and Graduate \\ Program in Botany, Institute of Biosciences-UFRGS, Porto Alegre, RS 91540-000, Brazil \\ ${ }^{3}$ Graduate Program in Design-PGDesign, Federal University of Rio Grande do Sul-UFRGS, Porto Alegre, RS 90035-190, Brazil; and Department of \\ Materials-DEMAT, Federal University of Rio Grande do Sul-UFRGS, Porto Alegre, RS 90035-190, Brazil \\ ${ }^{4}$ Department of Chemical and Materials Engineering-DEQM, Pontifical Catholic University of Rio de Janeiro-PUC-Rio, Rio de Janeiro, RJ 22453-900, \\ Brazil \\ ${ }^{5}$ Laboratory of Plant Anatomy-LAVeg, Department of Botany-Federal University of Rio Grande do Sul-UFRGS, Institute of Biosciences, Porto \\ Alegre, RS 91540-000, Brazil \\ ${ }^{6}$ Graduate Program in Design-PGDesign, Federal University of Rio Grande do Sul-UFRGS, Porto Alegre, RS 90035-190, Brazil; and Department of \\ Design and Graphic Expression-DEG, Federal University of Rio Grande do Sul-UFRGS, Porto Alegre, RS 90035-190, Brazil \\ ${ }^{a)}$ Address all correspondence to this author. e-mail: felipe.palombini@ufrgs.br \\ Received: 27 January 2019; accepted: 8 March 2019
}

Bamboo is a natural composite and one of the most efficient structures in nature because of the relationship of mechanical properties with its microstructural features. This research presents the 3D characterization of the reinforcement bundles of a branching nodal region of bamboo, through high-resolution X-ray microtomography $(\mu \mathrm{CT}) . \mu \mathrm{CT}$ was used to characterize a sample regarding the volume, relative density, and porosity of parenchyma and sclerenchyma tissues, and the resulting data were used to estimate their constitutive properties. A nonlinear finite element analysis (FEA) was performed based on a discretized model of the $\mu \mathrm{CT}$ to the limiting compressive load. Secondary bundles presented an interweaved arrangement into the primary vascular elements that distribute axial compressive stresses into new branches. Our findings suggest that the foam-like behavior of the parenchyma, the sclerenchyma thickening above the nodal zone, and the nodal vascular branching are ways for bamboo to protect important tissues from mechanical stress by allocating axial loads. In addition, such mechanism could be applied in the design of biomimetic structures with selective loadbearing capabilities.

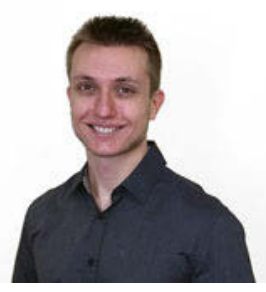

Felipe Luis Palombini
Felipe Palombini received his M.Sc. (2016) and his Ph.D. (2019) in the Graduate Program in Design (PGDesign), in the School of Engineering of the Federal University of Rio Grande do Sul (UFRGS), in Porto Alegre, Brazil. His research focused on biomimetic and bionic systems, including microstructural characterization and thermomechanical analyses of plants and natural materials, particularly bamboo (Bambusoideae) and bromeliads (Bromeliaceae), using high-resolution X-ray microtomography and finite element analysis. He is associated with the Virtual Design Laboratory (ViD) and the Plant Anatomy Laboratory (LAVeg) at UFRGS, and has worked as assistant professor at the Federal University of Santa Maria (UFSM), Brazil.

\section{Introduction}

Bamboo is one of the most efficient structures in nature, combining interesting mechanical properties with an overall low density, at multiple scales $[1,2]$. Figure 1 presents the plant's main macrostructural and microstructural features. Macroscopically, the plant's cylindrical stem is divided into 
regions of hollow internodes and solid nodes [3, 4] [Fig. 1(a)]. The vascular bundles in the stem appear broadly spaced and scattered throughout the fundamental tissue of the stem, following the monocotyledon arrangement, namely atactostele [5]. In the internodes, such arrangement in longitudinal vascular elements is observed by their distribution in a radial density gradient, increasing from the inner to the outer side of the plant [Fig. 1(b)], and then contributing to the culm stiffness $[6,7,8]$. On the other hand, the vascular elements also move transversally in the nodes, leading to solid sections (diaphragm) in the stem that prevent its structural failure by ovalization during bending $[9,10,11]$. Microscopically, the combination of different tissues with complementary properties supports the analogy of bamboo as a natural composite [12, 13, 14]. Vascular elements are encompassed and protected by sclerenchyma bundles, a tissue composed of lignified fibers cells, with thickened secondary cell walls, and surrounded by the parenchyma ground tissue, consisting of living cells with different shapes and physiological functions [Fig. 1(c)]. Although the denser and consequently stiffer sclerenchyma provides structural reinforcement, the parenchyma has been shown to behave like a foam and to distribute local stresses to the whole structure as a matrix [15, 16]. Despite recent efforts to characterize and study the mechanical behavior of internodal bamboo in the light of its microstructure $[17,18,19]$, the nodal region represents a far more complex arrangement of vascular bundles because of their need for rearrangement, especially in new vegetative and reproductive branches, thus requiring highresolution and noninvasive characterization approaches.

The constitutive properties of bamboo parenchyma and sclerenchyma can be estimated based on numerical models for the three-dimensional properties of porous materials [20], or cellular solids, following the pioneer studies of Gibson and Ashby [21], such as foams and honeycombs. Principally, such properties are related to the (i) shape and (ii) distribution of cells or pores, the (iii) thickness of their cell walls or edges, as well as the (iv) properties of the solid cell material $[2,22]$. Recently, such models were also used as a base to study the mechanical properties of several materials, such alumina [23], titanium [24], silica [25] and cellulose acetate [26] foams, and trabecular bone [27]. Moreover, those models were also used as a base for different approaches [28], such as the ones presented by Richardson et al. [29] and Buciuman et al. [30], mostly used for foam-like materials. The parenchyma can be morphologically characterized as a honeycomb because of its prismatic cellular configuration [2]. However, its mechanical behavior resembles that of a closed-cell foam with curved cell walls [16, 31]; therefore, the calculation of their mechanical properties has been assessed from 3D numerical models of such materials [15].

Characterizing the structural behavior of efficient plants like bamboo is essential for understanding its performance to apply such information in the development of improved bioinspired projects $[32,33,34]$. Particularly, the inclusion of solid sections, similar to nodes, in hollow structures, representing a simplified version of bamboo's diaphragm, has been shown to be a key part of the overall performance. For instance, Zou et al. [35] verified in a bamboo bioinspired structure that the nodes acted as joints and contributed to better energy-absorbing capabilities. Similarly, Zhao et al. [9] and Liu et al. [36] also demonstrated that node-like features can increase the performance of bionic or biomimetic structures. However, even with improvements observed in simplified versions of the diaphragm, the plant's actual nodal region has not been fully investigated either anatomically or biomechanically, i.e., by also considering the complex arrangement of vascular bundles in its structure, thereafter leading to divergences in the literature. Shao and Wang [37] showed that the nodes do reinforce bamboo culms at multiple loads, with the exception of longitudinal tension. In addition, Schulgasser and Witztum [11] found that the nodal region also prevents longitudinal crack propagations. On the other hand, Taylor et al. [38] affirmed that nodes would have to be closely spaced for a significant effect on the mechanical performance of the culm. Authors also suggested that nodes have evolved to avoid failure near the branch. Anatomically, Shao and Wang [37] affirmed that one part of the vascular bundles bends inward and outward, and then spreads along the original direction, whereas the other bundles spreads transversely. Liese and Tang [39] state that some vascular elements pass directly through the node, while connecting with others from the diaphragm. Then again, Taylor et al. [38] stated that once acting as branch points, the sclerenchyma bundles are forced to deviate from the longitudinal orientation in the nodes.

The complex arrangement of vascular bundles in the nodal region is a key topic for characterizing the morphostructural characteristics of bamboo, either for a better understanding of the material's behavior or for application in bioinspired projects. However, its 3D morphological reconstruction and mechanical role regarding its anatomy remain unexplored. Ding and Liese [40] presented a primary illustration of the structure of a bamboo node with emphasis on bridges and vascular anastomoses, based on physical serial sections of a sample. Another approach was conducted by Haushahn et al. [41], in which the nodal vascular bundles of a Dracaena reflexa sample (an arborescent monocotyledon) was segmented by aligning and digitalizing transversal serial sections, revealing the vascular arrangement of the nodal region in a $3 \mathrm{D}$ visualization. Both methods required physical sectioning of the samples, a destructive procedure that could damage delicate tissues. Therefore, noninvasive techniques have also been used, such as X-ray computed tomography (CT). Huang et al. [42] used CT to present longitudinal and transversal sections of the node of a Moso bamboo (Phyllostachys edulis) sample, still no 

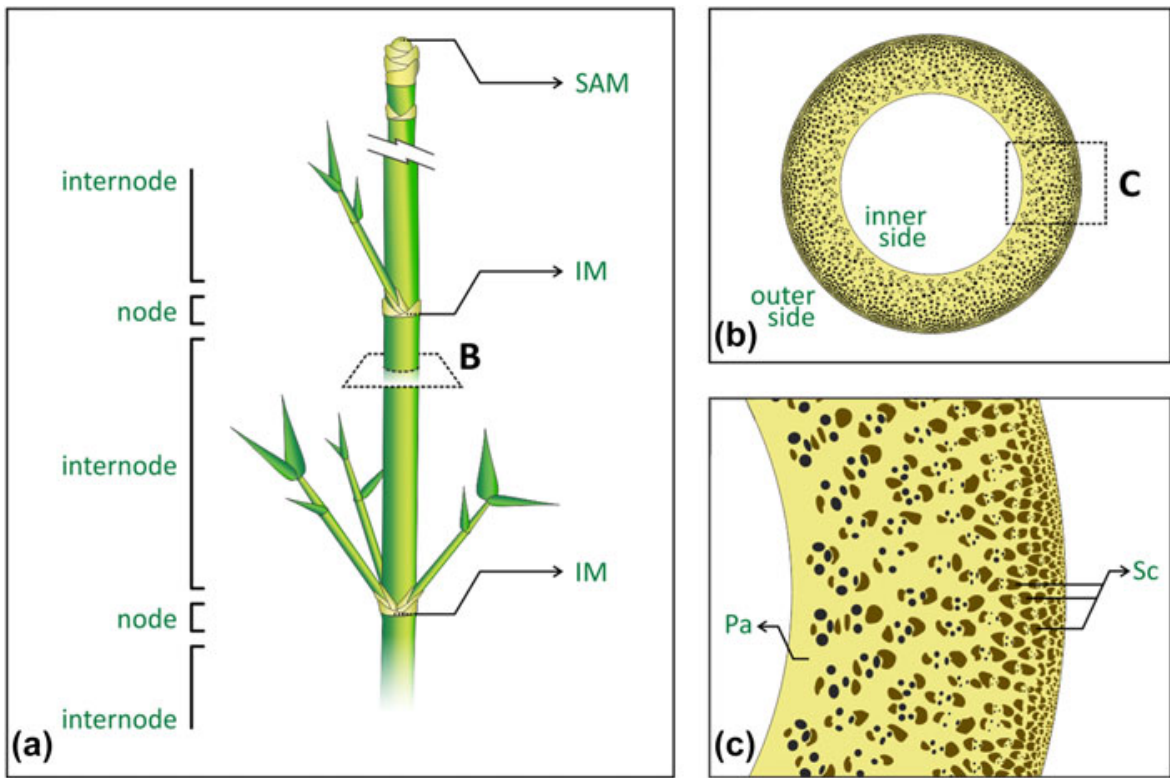

Figure 1: Bamboo main macrostructural and microstructural features: (a) stem segmentation of regions of nodes and internodes, where SAM is the shoot apical meristem, and IM is the intercalary meristem; (b) internode cross-section showing the atactostele gradient distribution of the vascular bundles, from the inner to the outer side of the stem; (c) tissues encompassing the vascular elements, where $\mathrm{Pa}$ is the parenchyma and Sc is the sclerenchyma bundles.

$3 \mathrm{D}$ visualization of the $\mu \mathrm{CT}$ stack was performed. Peng et al. [43] used X-ray microtomography $(\mu \mathrm{CT})$ in a bamboo sample (Pleioblastus gozadakensis) revealing a partial $3 \mathrm{D}$ view of the node, yet authors did not perform a segmentation procedure, thus impairing the actual visualization and the correct interpretation of the morphology of the vascular bundles.

In addition to a better visual analysis of a region of interest (ROI) of plants $[44,45]$, segmentation of $\mu \mathrm{CT}$ stack images allows such models to be exported to 3D file extensions, e.g., for application in $3 \mathrm{D}$ printing $[15,46,47]$ and finite element analysis (FEA) [16, 48]. Notably, Petit et al. [49] present a broad review and highlight the main applications of $\mu \mathrm{CT}$ and FEA for the study of cellular solids. In another review of FEA of natural fibers and composites reinforced with natural fibers, Xiong et al. [50] highlight the importance of considering the irregular cross-section of fibers to improve the accuracy of the analysis. Authors also comment on the benefits of importing the actual geometry directly from $\mu \mathrm{CT}$ as an approach to characterize the sample's microstructure. A $\mu$ CT-based FEA of the internode region of bamboo was also conducted [16] by considering the actual sclerenchyma distribution into the parenchyma under a compressive load. Results were comparable to those of experimental tests, although the nodal region was not represented. Silva et al. [51] modeled a two-node long bamboo stem for FEA and compared the constitutive properties of homogenized isotropic, orthotropic, and functionally graded material (FGM), which represents the atactostele distribution of vascular bundles. Authors verified that despite the higher computational effort, the model with FGM constitutive properties is needed for a more accurate estimate of stresses on the model. However, once the FGM was applied in the internode regions only, the vascular bundles of the diaphragm regions of the nodes were neglected. Consequently, those regions were analyzed with minimum mechanical properties and resulted in much smaller local stresses. Therefore, advances in high-resolution imaging methods linked to FEA in complex microstructural arrangements are essential to provide better insights not only into natural materials but also for the composite industry $[50,52]$.

This study presents the $3 \mathrm{D}$ characterization of the morphology and the structural analysis of a 4-axes nodal bamboo sample, regarding its anatomy in that region. High-resolution $\mu \mathrm{CT}$ was used to image the sample, which was then segmented according to the complex arrangement of the vascular bundles. The 3D model was characterized, including the assessment of the volume, porosity, relative density, and distribution of the plant's tissues and vascular bundles [16]. Relative density data from the parenchyma and the sclerenchyma were used to determine the constitutive properties of both tissues. Finally, a nonlinear FEA was performed using the actual distribution of the vascular bundles in the diaphragm to investigate the behavior of the nodal region under a compressive load.

\section{Results and discussion}

\section{Morphological analysis}

The $3 \mathrm{D}$ reconstruction of the bamboo nodal region with the secondary branches is presented in Fig. 2. Figures 2(a)-2(g), 


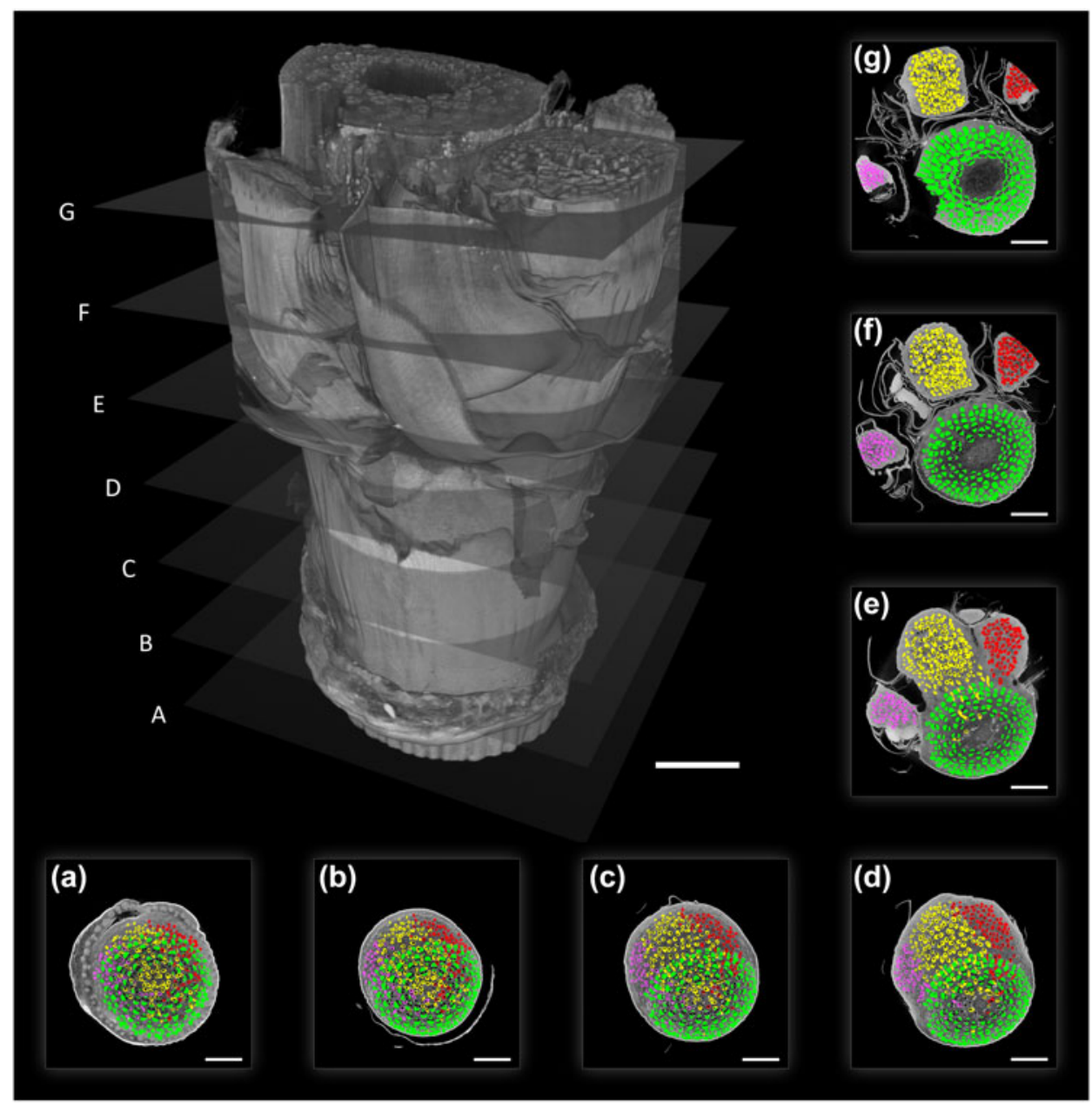

Figure 2: $\mu \mathrm{CT}$ 3D reconstruction of the nodal region of bamboo with secondary branches. Details a-g present $\mu \mathrm{CT}$ slices (from the bottom up of the sample) showing the development of leaves sheaths and stem branches, highlighting the anastomosis of vascular bundles while connecting the main axis (green) to the secondary axes (purple, yellow, and red). Scale bars $=1 \mathrm{~mm}$.

present the development of the branches into secondary axes, with the combination of binary masks of segmented vascular bundles and $\mu \mathrm{CT}$ slices distributed from the bottom up of the model. In the lower part of the diaphragm [Fig. 2(a)], the marginal vascular bundles leave the central cylinder, vascularizing the leaves sheaths; at the same time, other marginal bundles migrate out of the central cylinder, with the addition of marginal bundles from the region opposite from it, passing through the main bundles to the outside [Figs. 2(b)-2(d)].

As the reference $\mu \mathrm{CT}$ slice position approaches the top region of the diaphragm, vascular bundles of secondary axes are shown surrounding and enclosing the ones of the primary axis, while moving transversally [Fig. 2(c)], and start to align with their respective secondary branches [Fig. 2(d)], until found separated into branches [Fig. 2(e)]. It is noteworthy that most secondary bundles kept their transversal relative position in the secondary axis regarding the original scattered distribution of the primary one (atactostele). In addition, after distinctively separated into new axes in the upper part of the node [Fig. 2(f)], the vascular bundles of the primary axis exhibit a considerable thickening, by increasing in their transversal dimension, particularly in the axillary region of the main axis [Fig. 2(g)]. Such behavior is in accordance with the description of bamboo nodal structure reported by Liese and Tang [39] and Shao and Wang [37]. The development and horizontal movement of the vascular bundles can also be visualized in supplementary video (SV1) of $\mu \mathrm{CT}$ slices.

Figure 3 presents the $3 \mathrm{D}$ reconstruction of the vascular bundles segmented based on the $\mu \mathrm{CT}$ imaging. By hiding the bundles of the primary axis [Fig. 3(a)-green], the ones of the secondary axes (purple, yellow, and red) can be seen interweaving with them. Horizontal movement of the secondary bundles can be better observed in Fig. 3(b). While developing vertically through new branches, the bundles also move to the opposite direction of their respective axis before splitting into a new branching. Those characteristics can also be observed in 

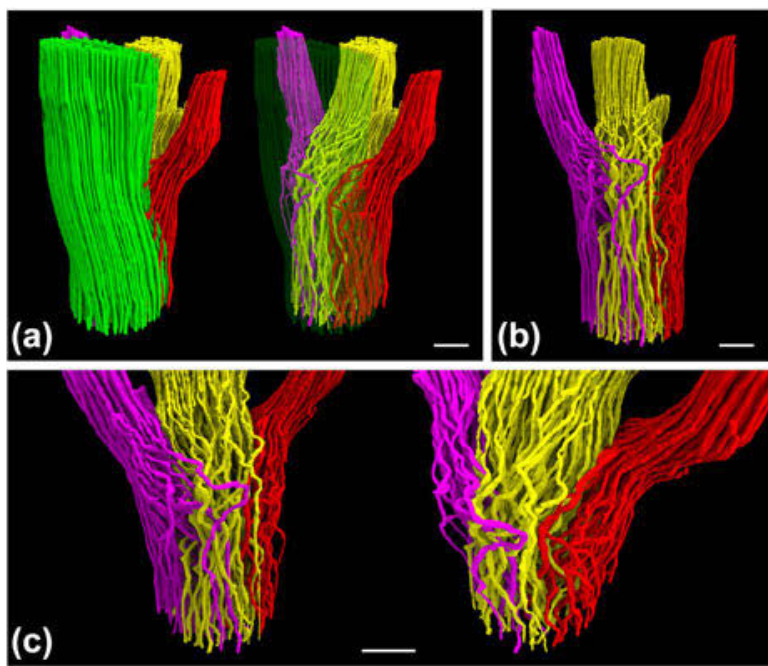

Figure 3: 3D reconstruction of vascular bundles from $\mu C T$ of the nodal bamboo region with secondary branching: (a) vascular bundles of the main axis interweaving with the ones of the secondary axes; (b) vascular bundles of the secondary axes only; (c) details of the transversal movement of secondary vascular bundles. Scale bars $=1 \mathrm{~mm}$.

Fig. 3(c), with the empty space regarding the hidden vascular bundles of the primary axis. Despite not presenting the sclerenchyma thickening above the nodal region, the interlocking of the secondary bundles also suggests a reinforced connection with the main axis. An interesting feature observed is the continuity of the secondary branches from the basal portion until the branching, without bridges, or vascular traces, connecting the secondary axes with the main axis. Such structures develop in the internode, below the nodal region [16].

Total volume, relative density, and porosity of the segmented regions of sclerenchyma and parenchyma were quantified. The relationship of those values with each $\mu \mathrm{CT}$ transversal slice position is presented in Fig. 4. Parenchyma presented an absolute volume of approximately $57.4 \mathrm{~mm}^{3}$, with an average relative density of 0.317 , and, consequently, a porosity of $68.3 \%$. Sclerenchyma resulted in an absolute volume of around $28.4 \mathrm{~mm}^{3}$, which can be divided into the main axis, $15.4 \mathrm{~mm}^{3}$, and the three secondary axes, or $2.2 \mathrm{~mm}^{3}, 7.5 \mathrm{~mm}^{3}$, and $3.3 \mathrm{~mm}^{3}$. The tissue also presented a relative density of approximately 0.860 , giving a porosity of approximately $14 \%$. Values were generally similar to those reported in the literature $[12,16,53]$. The sample consisted of approximately 415 vascular bundles distributed in the main and secondary axes. Individually, the bundles presented an average volume of approximately $0.102( \pm 0.013) \mathrm{mm}^{3}$, average cross-section area of $0.011( \pm 0.002) \mathrm{mm}^{2}$, and average thickness of 155.514 $( \pm 14.861) \mu \mathrm{m}$, approximately, calculated by the Analyze Particles tool and the 3D Objects Counter plugin [54].

Overall, the relative density of the parenchyma and sclerenchyma follows a similar pattern from the bottom to

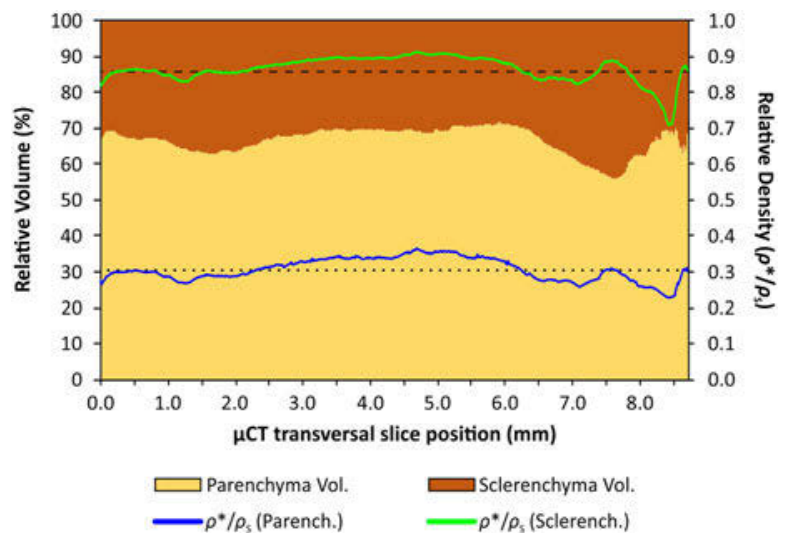

Figure 4: Relative volume (\%) and relative density $\left(\rho^{*} / \rho_{\mathrm{s}}\right)$ of parenchyma and sclerenchyma related to each transversal slice position of the $\mu \mathrm{CT}$-segmented nodal bamboo. Dotted and dashed lines represent the average values of $\rho^{*} / \rho_{\mathrm{S}}$ for the parenchyma and sclerenchyma, respectively.

the top of the sample. In addition, by relating the relative density data of Fig. 4 with the sequential slices of Fig. 2, some density characteristics of bamboo tissues can be listed. The slight decrease of the $\left(\rho^{*} / \rho_{S}\right)$ after $1 \mathrm{~mm}$, in the lower part of the node, regards the start of scattering of secondary bundles into new axes, seen in Figs. 2(a) and 2(b). Relative density then increases for both tissues until the slice position reaches approximately $5 \mathrm{~mm}$, in the upper part of the node, corresponding to Figs. 2(d) and 2(e). Such behavior indicates that by developing new vascular bundles, bamboo sclerenchyma cells tend to thicken or get more lignified. At the $7 \mathrm{~mm}$ slice position, after a physical detachment of the main axis into three secondary branches [Fig. 2(f)], an increase of the cell lumina is noticed, reducing the relative density. Finally, in the region right above the nodal region [Fig. $2(\mathrm{~g})]$, the sclerenchyma thickening of the main axis resulted in a larger relative volume and a greater relative density, before the slice position of $8 \mathrm{~mm}$. This may suggest a stiffness increase in that bamboo region. The last decrease of $\left(\rho^{*} / \rho_{S}\right)$ after that is related to the end of the sample positioning in the $\mu \mathrm{CT}$ field of view. Regarding the vascular bundles, calculated by the Analyze Particles tool, their average cross-section area and thickness decrease roughly $25 \%$ with the relative increase of the sclerenchyma, and they increase while the sclerenchyma bundles are slenderer. As expected $[5,55]$, such behavior indicates that a sclerenchyma thickening induces a constriction in the vascular elements in key points, where the secondary axes are physically divided from the primary one.

\section{Finite element analysis}

The discretizing process of the $3 \mathrm{D}$ segmented model of the nodal region of bamboo focused on the shape of the vascular bundles, mostly represented by the sclerenchyma. The ground volume, corresponding to the parenchyma, involved the 
sclerenchyma, following the main and secondary axes. Because of the proceeding of a nonlinear FEA, where the maximum compressive load is assessed, leaves' sheaths and other external fine structures were suppressed from the $3 \mathrm{D}$ model during segmentation, to avoid excessively local stresses that could underestimate the overall result, in addition to increasing the total number of elements in the mesh. Figure 5 shows the result of the discretizing process of the nodal bamboo. The assembly model [Fig. 5(a)] was divided into the parenchyma and sclerenchyma parts, shown in white and green respectively. Figure 5(b) presents the sclerenchyma elements only, by hiding the parenchyma part.

The entire assembly model consisted of a single tetrahedral mesh (type C3D4) with approximately 22 million elements and about 3.6 million nodes [Fig. 5(c)]. Two materials and sections were defined based on the elements of the sclerenchyma and the parenchyma, being set to the mesh. A fine mesh with a uniform element size was required because of the geometry of sclerenchyma bundles. To avoid an even more refined mesh, vascular elements of phloem and xylem were suppressed. Such details would require a considerably greater number of mesh elements and, consequently, more computational resources on solving the analysis.

Using Eqs. (1)-(4), the constitutive properties for the parenchyma and sclerenchyma tissues were defined based on their respective relative density data. Elastic modulus resulted in approximately $4.0 \mathrm{GPa}$ for the parenchyma and $34.2 \mathrm{GPa}$ for the sclerenchyma, as well as the values of $25.3 \mathrm{MPa}$ and 213.3 $\mathrm{MPa}$ for their compressive strength, respectively. Once the orientation of the sclerenchyma bundles into the geometry was defined by the mesh elements distribution, the tissue was already presented in a slender, fiber-like configuration. Therefore, both materials were set as isotropic using the above materials properties.

The initial total force pressure loading of $100 \mathrm{MPa}$ applied in the model showed a maximum load increment of 0.6207 , and for bigger values, there was no convergence in the FEA. Next, a second analysis was performed, adjusting the loading to the maximum increment value reported. The model then converged to a maximum axial compressive strength of approximately $62 \mathrm{MPa}$. The result is in the same range of those in the literature for physical tests of Bambusa tuldoides. For instance, Colli et al. [56] found compressive strength values ranging from $46 \mathrm{MPa}$ to about $72 \mathrm{MPa}$ for samples located at nodal regions, from the base to the top portion of the culm. Nascimento et al. [57] found compressive values from 65.8 to 88.2 MPa. Conversely, But and Chia [58] data report compressive values of around $30 \mathrm{MPa}$ in the nodal region, and Janssen [59] found values ranging from 27 to $43 \mathrm{MPa}$. However, such variation is not surprising and can somewhat be expected because of the natural variability of bamboo, as
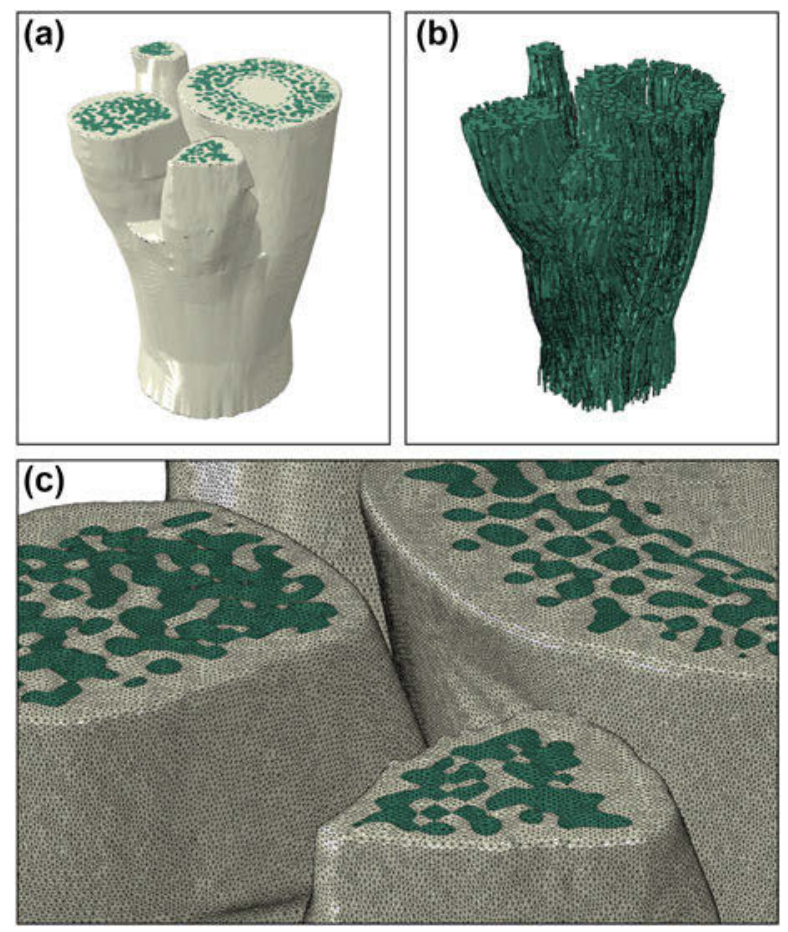

Figure 5: Meshing process for the FEA of the $\mu \mathrm{CT}$-based nodal region of bamboo: (a) discretized assembly model with the regions of parenchyma (white) and sclerenchyma (green); (b) sclerenchyma region only, by hiding the parenchyma mesh elements; (c) detail of the tetrahedral mesh of the assembly. Mesh elements contours were hidden in $A$ and $B$ to improve the visualization of the $3 \mathrm{D}$ model.

well as the several controlled factors, such as the sample maturity and position in the culm, collecting and drying protocols, among others $[1,4,16]$. Therefore, in $\mu$ CT-based FEA of plants, qualitative results of the analysis can be considered important as well, in terms of investigating the complex mechanical behavior of the sample.

The von Mises stress results at the compressive failure of the converged FEA are presented in Fig. 6. Because of differences in range values of the von Mises stresses legends from the parenchyma and sclerenchyma sets (automatically recalculated based on their respective limiting values of $\sigma_{\mathrm{P}}$ and $\sigma_{\mathrm{Sc}}$ ) as well as for a better visualization, tissues were presented separately. The parenchyma model and its internal view cut are shown in Fig. 6(a). Higher stressed zones were mostly noticed in lower branching regions of secondary axes, in addition to the upper face of the assembly, where the compressive load was applied. Secondary axes were also more stressed in the connecting regions among other branches. Despite having a considerable amount of sclerenchyma bundles, though, the inner zone of the bottom part of the sample presented lower stress levels.

Although activating several sclerenchyma reinforcement bundles in all axes [Fig. 6(b)], the parenchyma presented less stressed regions in the primary one. Besides dissipating the compressive stress among the entire sample, and then 
(a)
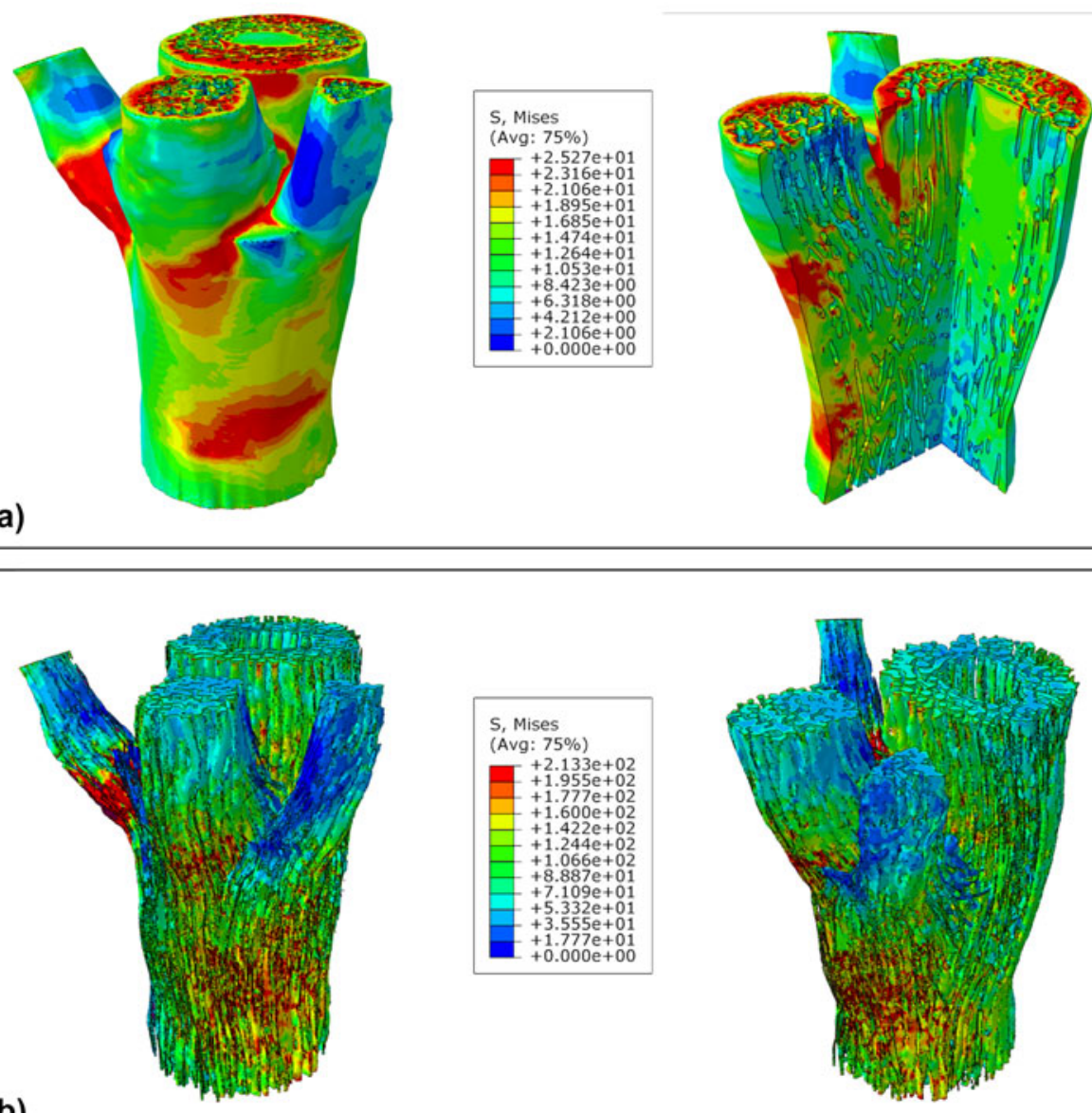

(b)

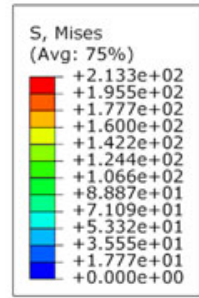

Figure 6: The von Mises stress results at the compressive failure of the $\mu$ CT-based FEA of the nodal region of bamboo: (a) parenchyma elements set only, and internal view cut; (b) sclerenchyma elements set only. Mesh elements contours were hidden to improve the visualization of the colored regions.

mechanically acting as a foamy matrix in a composite analogy $[15,16]$, such behavior indicates a tendency for the parenchyma to preserve its primary axis. Even with a uniform distribution of the compressive pressure, with most stressed regions concentrated in secondary axes, it can be inferred that the plant would tend to protect their main axis with their intercalary meristem (IM), an embryonic tissue founded between mature tissues, in bamboo at the base of the internode; and the shoot apical meristem (SAM), the terminal part of the shoot immediately above the uppermost leaf primordium [Fig. 1(a)]. Although each branch also has an IM and a SAM, in the main axis, these meristems hold a dominant control answering for the plant architecture [60]. Moreover, the thickening of sclerenchyma bundles in the top portion of the primary axis, observed in the $\mu \mathrm{CT}$ and relative density analyses, shows that this region was older than the branching portion and then received additional secondary cell wall deposition. In addition, the dominant control of the main axis presents an effort for the plant to increase the strength in that region; with larger bundle transversal areas, von Mises stress distribution tends to be relatively smaller [61, 62], as seen in the results.

Our findings regarding the mechanical role of the nodes in bamboo support those of Shao and Wang [37] and Zou et al. [35], once such regions improve the dissipation of stresses and reinforce the overall culm at compressive loads. Similar to the conclusions of Taylor et al. [38], related to the evolution of bamboo nodes to prevent failure in the vicinity of the branch, our results suggest that the plant tends to preserve the primary axis at compressive loads, leading greater stresses to be transferred to the secondary branches. Anatomically, such behavior would allow the development of lateral structures, such as branches and leaves, without compromising the strength of the primary axis [5]. Also, the longitudinal and transversal spreads of vascular bundles in the node, in addition to the sclerenchyma thickening, were also in accordance with the literature $[37,39]$, but not their origin, as demonstrated here in $3 \mathrm{D}$ model for the first time. On the other hand, it is noteworthy that some characteristics reported in the literature, regarding the $3 \mathrm{D}$ arrangement of vascular bundles in the nodal region of 
bamboo, were not observed in our $\mu \mathrm{CT}$ reconstruction. Particularly, the presence of vascular bridges and branching anastomosis at the diaphragm [40] were observed to actually develop below the nodal zone [16]. Then, again, such configuration may also represent a way for the plant to protect important developing tissues [3]. Finally, the fiber bundles interweaved configuration could be also explored in bambooinspired bionic designs $[9,36]$ to induce the stress distribution into regions of interest and by preventing particular regions from overstressing.

\section{Conclusions}

The branching morphology and the mechanical behavior of the nodal region of bamboo were assessed using high-resolution $\mu \mathrm{CT}$ and a nonlinear FEA using the $3 \mathrm{D}$ reconstructed model. We propose a relationship of the complex bamboo anatomy with its structural behavior under the maximum compressive load. The main contribution of the research is to present one of the first 3D microstructural reconstructions of the complex nodal vascular system of monocots, by means of identifying its arrangement within the node and tracking the lateral movements of the bundles, in addition to evaluating its role in distributing uniform axial stresses in the stem. Data from the $\mu \mathrm{CT}$ characterization were used to estimate the constitutive properties of each tissue and also to assist in the interpretation of the FEA model.

Bamboo vascular elements in the nodal region were characterized as a complex arrangement of bundles that connect and interweave the primary axis to those of the secondary ones. By originating below the basal node, marginal secondary vascular trace bundles can be considered a way for the plant to develop lateral branches whereas protecting the main axis from mechanical stresses. The increase of sclerenchyma relative volume in the stem after branching, in addition to the thickening of fiber bundles, was observed in the $\mu \mathrm{CT}$ imaging and reconstruction. Such characteristics were related to a reinforcement above the node to increase the local strength of the plant. Although moving from the marginal traces, transversally and across the primary vascular elements, the secondary bundles tend to preserve their relative final position in the branch similar to their original location when in the primary axis. $\mu \mathrm{CT}$ reconstruction also allowed to visualize the real development of the bundles and then to compare to features described in the literature, based on more traditional sequential cutting techniques.

$\mu \mathrm{CT}$-based FEA showed to be an important way to analyze the qualitative aspects of the microstructure of plants. Results of the nonlinear FEA presented a maximum value for the axial compressive strength in agreement to physical tests reported in the literature for $B$. tuldoides. However, as seen in the broad range in the referred data, several variables may influence the strength of a bamboo sample. Therefore, the $\mu$ CT-based FEA approach can be better used as a tool for assessing the microstructural performance of the sample. Our findings reinforce the known foam-like matrix behavior of the parenchyma, by distributing stresses and mechanically activating the reinforcement sclerenchyma bundles along the stem. Higher stressed regions were mostly found in the secondary axes during compression, specifically in their lower regions and in the interconnecting zones among other branches. Over the maximum compressive load, bamboo was assessed as having the tendency to transfer stresses to the lateral branches to preserve the lower and central regions of the main axis, given that those regions include important development tissues for the plant, as the intercalary meristem and the SAM. The characterized bundles configuration may also be studied for the design of innovative biomimetic designs, by inducing local regions of a jointed structure to be preserved over a global mechanical failure. Particularly, with such a bioinspired reinforcement network, a structure could be designed to collapse at specific zones, when overloaded. The selective load-bearing capabilities of bamboo can also be used to assist the prediction of a safely global failure mode of a structure, meanwhile preserving local spots.

\section{Materials and methods}

\section{Sample preparation}

A sample of B. tuldoides Munro was collected from the state of Rio Grande do Sul in Southern Brazil. B. tuldoides is native to southern China and Vietnam, having been introduced and cultivated in Central and South America [63]. The species reaches approximately up to $10-12 \mathrm{~m}$ in height, and its stem reaches $3-5 \mathrm{~cm}$ in diameter [16]. The chosen ROI was the apical stem of a mature plant (Fig. 7), with lignified sclerenchyma cell walls, because of the development of secondary axes in the nodal region [Fig. 7(a)] and consequently the presence of vascular anastomosis. Naturally, once the sample was collected from the top portion of the stem, it consisted of a relatively small specimen [Fig. 7(b)]. A smaller sample facilitates $\mu \mathrm{CT}$ image acquisition and leads to better resolution.

The sample was manually sectioned transversally above the nodal region, with a scalpel [Fig. 7(c)]. Because of its apical position in the stem, sclerenchyma cell walls presented a less lignified level; therefore, no softening protocol was necessary for an even sectioning. The sample was then fixed in $\mathrm{FAA}_{50}$ (adapted from [64]), composed of five parts of formalin, five parts of acetic acid, and 90 parts of 50\% ethanol (v/v) [65] and kept soaked for 7 days. After rinsing in water, the sample was immersed in $50 \%$ ethanol for $1 \mathrm{~h}$ and passed to $70 \%$ ethanol for a further $1 \mathrm{~h}$. It was then immersed in 2,2-dimethoxypropane 

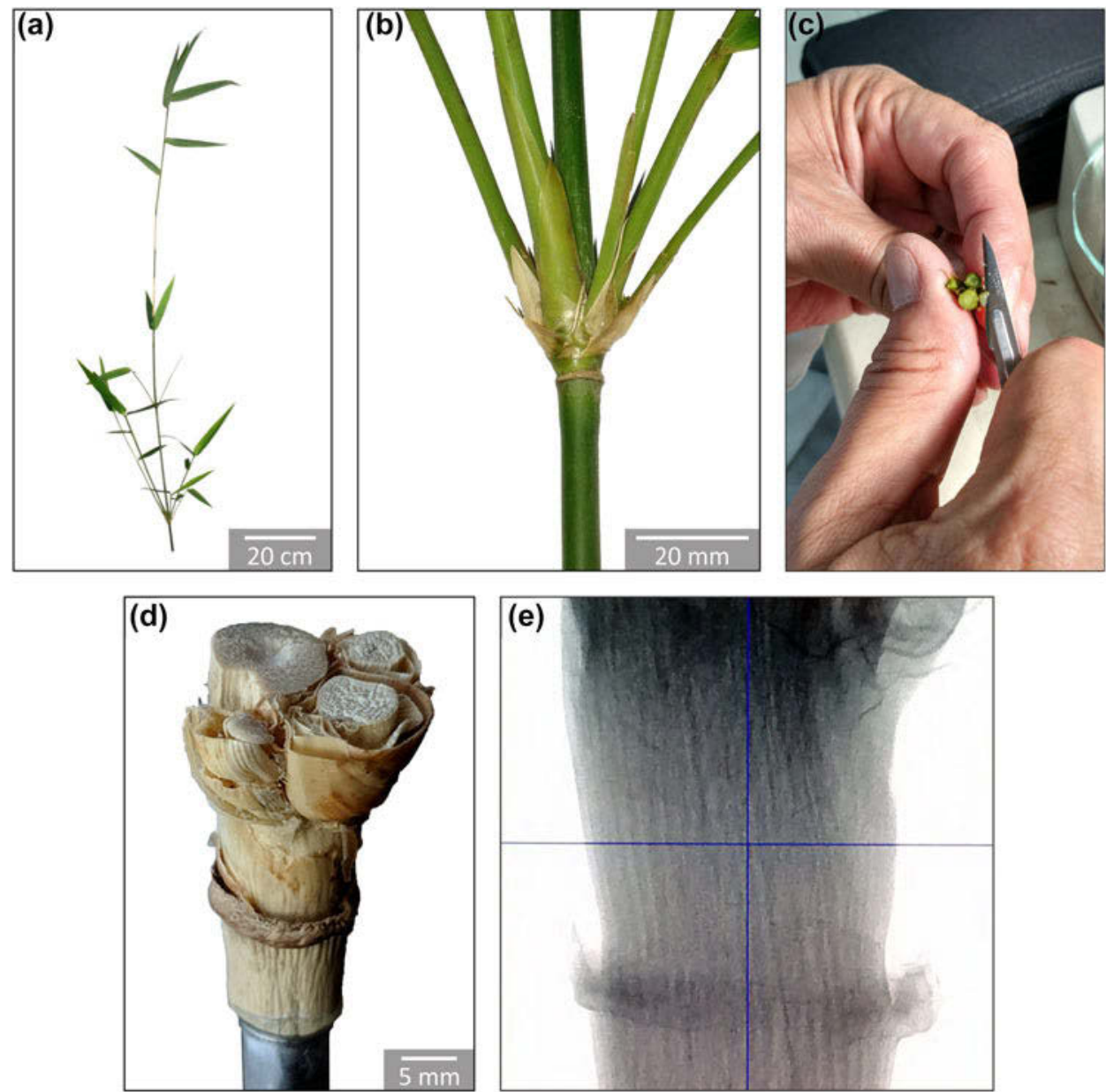

Figure 7: Sample preparation of bamboo (B. tuldoides) for X-ray microtomography: (a) top portion of the stem; (b) nodal region of the apical stem of the specimen, consisted of a primary axis generating lateral sheaths and buds; (c) cross-sectioning of the sample; (d) sectioned sample; (e) $\mu \mathrm{CT}$ projection.

for $24 \mathrm{~h}$ as an intermediary method in the drying process [16]. Finally, it was kept in a dehumidifying cabinet for 2 days to finish drying.

\section{X-ray microtomography $(\mu \mathrm{CT})$}

X-ray microtomography $(\mu \mathrm{CT})$ is a noninvasive, highresolution method to acquire a $3 \mathrm{D}$ imaging of a sample based on the attenuation of the radiation, allowing further analyses [66]. 3D imaging acquisition was conducted in a Zeiss Xradia 510 Versa CT (Zeiss X-ray Microscopy, Pleasanton, California). Because of the overall small size of the bamboo sample [Fig. 7(d)], it was possible to place it entirely within the field of view of the equipment. Fitting the sample in the field of view reduces artifacts, leading to optimal results in the analysis [67, 68]. The 510 Versa has a sealed transmission source that reaches $160 \mathrm{kV}$ and $10 \mathrm{~W}$, combining geometric and optical magnification. Therefore, it was possible to zoom in to adjust the field of view to the ROI. Using an objective lens of $4 \times$, the bamboo sample was scanned with an X-ray source voltage and current of $80 \mathrm{kV}$ and $88 \mu \mathrm{A}$, for a voxel size of $5.611 \mu \mathrm{m}$ after binning (source-sample distance $=40 \mathrm{~mm}$, sample-detector distance $=8 \mathrm{~mm}$ ). LE1 X-ray filtering was used to reduce beam hardening. Two acquisition sets (upper and lower parts) were performed to scan the sample. A total of 1601 projections [Fig. $7(\mathrm{e})$ ] in $0.225^{\circ}$ steps were obtained with $1 \mathrm{~s}$ exposure time for each set, resulting in a total acquisition time of $2 \mathrm{~h} 15 \mathrm{~min}$.

Image slices were combined and reconstructed from the projections with a noniterative filtered backprojection algorithm in the software provided by the manufacturer and exported as a stack of DICOM images. Images were processed and analyzed with the open-source Fiji software, a distribution of ImageJ [69], and processing steps are shown in Fig. 8. The original DICOM stack [Fig. 8(a)] was first enhanced with the non-local means [70] noise reduction filter [Fig. 8(b)], an edge-preserving low-pass filter. Figures $8(\mathrm{a} 1)$ and $8(\mathrm{~b} 1)$ demonstrate details of the same slice region before and after noise reduction processing, respectively.

For a better visualization in addition to an accurate analysis of bamboo vascular bundles in the nodal region, the sclerenchyma bundles were segmented manually and individually 
[Fig. 8(c)]. Once bamboo bundles tend to bend and shift transversally, tracking and identifying their origin and displacement is rather difficult. Therefore, each axis was also segmented independently, being divided into the primary axis and the three secondary axes. The segmentation editor plugin [69] was used in the process, also generating binary masks that could be exported and analyzed. Cell lumina regions of the conducting elements of xylem and phloem were preserved, by subtracting an additional lumina mask from the segmented binary masks, using the Image Calculator operation in Fiji. The vascular bundles were also quantified in terms of total number, average volume, cross section area, and thickness, using Analyze Particles tool and the 3D Objects Counter plugin for Fiji [54]. Finally, the resulting binary masks [Fig. 8(d)] were exported into binary STL files, according to each axis, for further morphological analyses.

\section{Finite element analysis (FEA)}

To assess the mechanical behavior of nodal bamboo region, a FEA was performed in the processed $\mu \mathrm{CT}$ stack. The discretization process of STL files into a volume mesh was performed with Gmsh [71], a free automatic 3D finite element mesh generator. A single mesh was used to discretize the $\mu \mathrm{CT}$ bamboo sample; however, group elements were attributed to the parenchyma and sclerenchyma regions for independent constitutive properties. To reduce the overall number of elements in the discretized mesh, xylem and phloem lumina void regions were removed from the vascular bundles. Such details would force the mesh size to an even more refined contour, significantly increasing the number of elements and thus requiring more processing power to solve the FEA. The volume mesh was exported to INP model file extension from Abaqus/CAE (Dassault Systèmes Simulia ${ }^{\circledR}$ Corp., Providence, Rhode Island) FEA software.

As cellular solids, modeling the 3D mechanical properties of bamboo tissues considers their relative density $\left(\rho^{*} / \rho_{\mathrm{S}}\right)^{2}$, and such data can be extracted from the $\mu \mathrm{CT}$ processed images [16]. The value represents the volume fraction of a region or the density of the cellular material $\left(\rho^{*}\right)$ divided by that of the solid cell wall material $\left(\rho_{\mathrm{S}}\right)$. Therefore, it can also be related to the porosity or the void fraction of the region $\left(1-\rho^{\star} / \rho_{\mathrm{S}}\right)^{2}$. Relative density data were assessed for the plant tissues with a binary mask of the stack and calculating the amount of volume for each region with Fiji. The elastic moduli of the parenchyma $\left(E_{\mathrm{P}}\right)$ and the sclerenchyma $\left(E_{\mathrm{Sc}}\right)$ were defined by [16]

$$
E_{\mathrm{P}}=\left(\frac{\rho^{*}}{\rho_{\mathrm{S}}}\right)_{\mathrm{P}}^{2} E_{\mathrm{s}}
$$
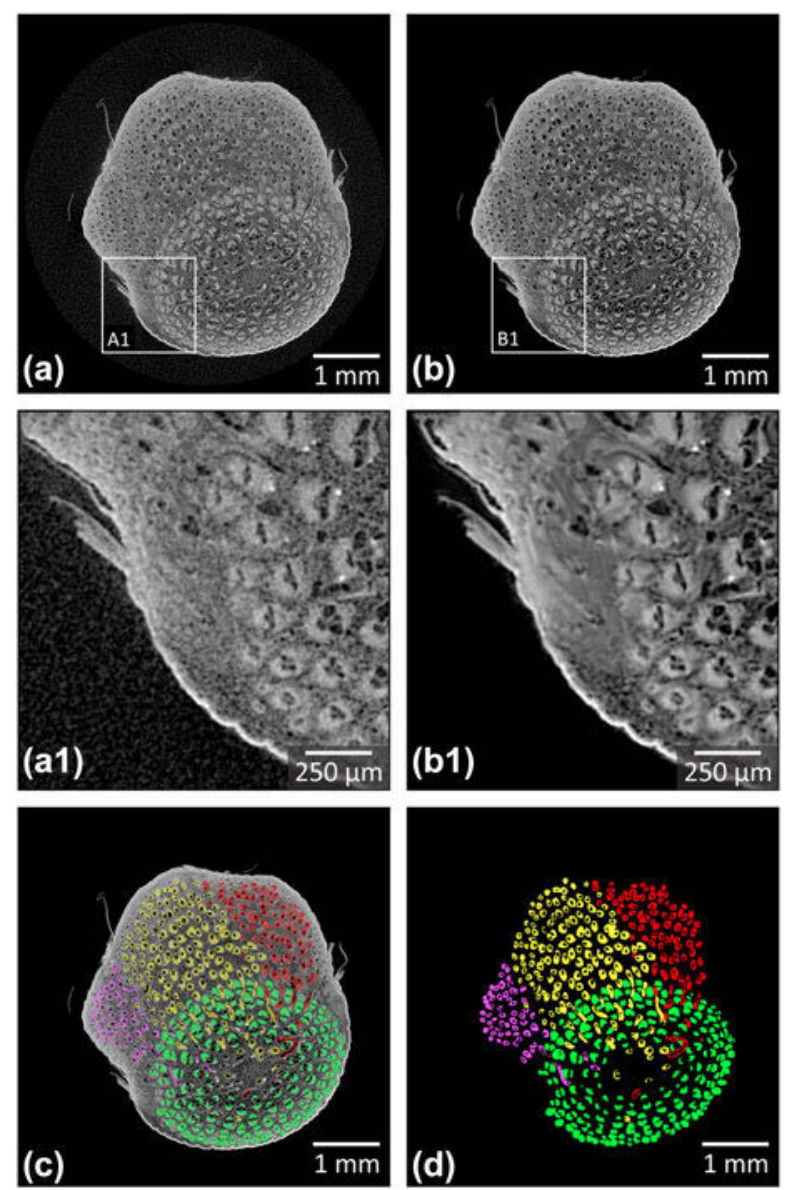

Figure 8: X-ray microtomography image stack processing on nodal bamboo sample: (a) original slice and detail (a1) of the noise in a region; (b) image filtered with non-local means denoising filter and detail (b1) of the same region after noise reduction; (c) manually segmented sclerenchyma of vascular bundles from primary axis (green) and secondary axes (purple, yellow, and red); (d) binary masks of segmented bundles.

$$
E_{\mathrm{Sc}}=\left(\frac{\rho^{*}}{\rho_{\mathrm{S}}}\right)_{\mathrm{Sc}} E_{\mathrm{s}},
$$

where $E_{\mathrm{s}}$ is the elastic modulus of the solid cell wall material of bamboo, or approximately $39.8 \mathrm{GPa}[16,31]$, and $\left(\rho^{*} / \rho_{\mathrm{S}}\right)_{\mathrm{P}}$ and $\left(\rho^{*} / \rho_{S}\right)_{S c}$ are the relative density for the parenchyma and the sclerenchyma, respectively. The power relationship of parenchyma's relative density to its elastic modulus is due to the tissue's geometric characteristics of a closed cell foam [2]. Because of the relative slenderness of the sclerenchyma bundles in the whole model, in addition to their irregular orientation along the diaphragm, the tissue was assumed as an isotropic material. Even though fiber cells are known to be an orthotropic material in a greater resolution [16], attributing an orthotropic material to small fiber bundles would require partitioning the sclerenchyma model into multiple regions with unique orientations in Abaqus/CAE, in addition to increasing the computational effort of the analysis. 
In this study, a nonlinear FEA was conducted to verify the mechanical behavior of the nodal bamboo sample during a compressive loading. Hence, nonlinear constitutive properties were also added to the model. The compressive strength values for the parenchyma $\left(\sigma_{\mathrm{P}}\right)$ and the sclerenchyma $\left(\sigma_{\mathrm{Sc}}\right)$ were also dependent on their relative density and can be defined according to

$$
\begin{gathered}
\sigma_{\mathrm{P}}=0.3\left(\frac{\rho^{*}}{\rho_{\mathrm{S}}}\right)_{\mathrm{P}}^{3 / 2} \sigma_{\mathrm{fs}}, \\
\sigma_{\mathrm{Sc}}=\left(\frac{\rho^{*}}{\rho_{\mathrm{S}}}\right)_{\mathrm{Sc}} \sigma_{\mathrm{s}},
\end{gathered}
$$

where $\sigma_{\mathrm{fs}}$ is the modulus of rupture of bamboo solid cell wall material, being defined as $472 \mathrm{MPa}$, and $\sigma_{\mathrm{s}}$ is the axial compressive strength of the solid cell wall material, defined as $248 \mathrm{MPa}[16,31] . \sigma_{\mathrm{fs}}$ is used for the parenchyma because of the foam-like characteristic, assuming cell wall bending and failure by plastic hinges under uniaxial stresses $[2,16]$. The 0.3 constant in Eq. (3) represents the fitting data results for the foam model during plastic collapse [2]. Poisson ratio set for the parenchyma and sclerenchyma was 0.4 and 0.22 , respectively [16].

An elastoplastic regime was set in the analysis, with the purpose of investigating the stresses and strains in the nodal bamboo model during the maximum compressive load supported. An initial axial compressive load of $100 \mathrm{MPa}$, defined as total force, was distributed in the top cross-section face of the model. The analysis was executed until converging to a maximum compressive load. The bottom face of the model was constrained as encastre. Finally, a self-contact property (surface-to-surface interaction, frictionless) was set in the model to prevent neighboring regions to intersect during loading.

\section{Acknowledgments}

This study was financed in part by the Coordenação de Aperfeiçoamento de Pessoal de Nível Superior-Brasil (CAPES)_Finance Code 001. This research was supported by the National Council for Scientific and Technological Development (CNPq-Brazil), the PROPESQ-UFRGS, and the Research Support Foundation of Rio Grande do Sul (FAPERGS). Authors thank Dr. Marcos Henrique de Pinho Mauricio, from DEQM PUC-Rio, and Dr. Haimon Dinis Lopes Alves, from UERJ, for the $\mu \mathrm{CT}$ image acquisition.

\section{References}

1. K.J. Niklas: Plant Biomechanics: An Engineering Approach to Plant Form and Function (University of Chicago Press, Chicago, 1992).

2. L.J. Gibson, M.F. Ashby, and B.A. Harley: Cellular Materials in Nature and Medicine (Cambridge University Press, Cambridge, U.K., 2010).
3. F.A. McClure: The Bamboos: A Fresh Perspective (Harvard University Press, Cambridge, U.K., 1966).

4. W. Liese: The Anatomy of Bamboo Culms (BRILL, Beijing, 1998).

5. A. Fahn: Plant Anatomy, Fourth (Pergamon Press, Oxford, 1990).

6. P.M. Rich: Mechanical structure of the stem of arborescent palms. Bot. Gaz. 148, 42 (1987).

7. U.G.K. Wegst: Bending efficiency through property gradients in bamboo, palm, and wood-based composites. J. Mech. Behav Biomed. Mater. 4, 744 (2011)

8. H. Li and S. Shen: The mechanical properties of bamboo and vascular bundles. J. Mater. Res. 26, 2749 (2011).

9. L. Zhao, W. Chen, J. Ma, and Y. Yang: Structural bionic design and experimental verification of a machine tool column. J. Bionic Eng. 5, 46 (2008).

10. U.G.K. Wegst and M.F. Ashby: The structural efficiency of orthotropic stalks, stems and tubes. J. Mater. Sci. 42, 9005 (2007)

11. K. Schulgasser and A. Witztum: On the strength, stiffness and stability of tubular plant stems and leaves. J. Theor. Biol. 155, 497 (1992).

12. S. Amada, T. Munekata, Y. Nagase, Y. Ichikawa, A. Kirigai, and Y. Zhifei: The mechanical structures of bamboos in viewpoint of functionally gradient and composite materials. J. Compos. Mater. 30, 800 (1996).

13. S.C. Lakkad and J.M. Patel: Mechanical properties of bamboo, a natural composite. Fibre Sci. Technol. 14, 319 (1981).

14. I.M. Low, Z.Y. Che, and B.A. Latella: Mapping the structure, composition and mechanical properties of bamboo. J. Mater. Res. 21, 1969 (2006).

15. P.G. Dixon, J.T. Muth, X. Xiao, M.A. Skylar-Scott, J.A. Lewis, and L.J. Gibson: 3D printed structures for modeling the Young's modulus of bamboo parenchyma. Acta Biomater. 68, 90 (2018).

16. F.L. Palombini, W. Kindlein, B.F. de Oliveira, and J.E. de Araujo Mariath: Bionics and design: 3D microstructural characterization and numerical analysis of bamboo based on X-ray microtomography. Mater. Charact. 120, 357 (2016).

17. P. Ghysels, G. Samaey, B. Tijskens, P. Van Liedekerke, H. Ramon, and D. Roose: Multi-scale simulation of plant tissue deformation using a model for individual cell mechanics. Phys. Biol. 6, 16009 (2009).

18. I. Burgert: Exploring the micromechanical design of plant cell walls. Am. J. Bot. 93, 1391 (2006).

19. W.S. Fu, Z.R. Zhao, W. Han, and J.B. Zhou: Research on finite element model for parallel to bamboo culms axial shear. Appl. Mech. Mater. 477-478, 986 (2013).

20. P. Colombo, D.C. Dunand, and V. Kumar: Porous materials: Less is more. J. Mater. Res. 28, 2187 (2013)

21. L.J. Gibson and M.F. Ashby: The mechanics of three-dimensional cellular materials. Proc. R. Soc. A 382, 43 (1982).

22. L.J. Gibson and M.F. Ashby: Cellular Solids: Structure and Properties, 2nd ed. (Cambridge University Press, Cambridge, U.K., 1999). 
23. B.S.M. Seeber, U.T. Gonzenbach, and L.J. Gauckler: Mechanical properties of highly porous alumina foams. J. Mater. Res. 28, 2281 (2013).

24. C.E. Wen, Y. Yamada, K. Shimojima, Y. Chino, H. Hosokawa, and M. Mabuchi: Novel titanium foam for bone tissue engineering. J. Mater. Res. 17, 2633 (2002).

25. Y. Toivola, A. Stein, and R.F. Cook: Depth-sensing indentation response of ordered silica foam. J. Mater. Res. 19, 260 (2004).

26. S. Zepnik, S. Hendriks, S. Kabasci, and H-J. Radusch: Foam extrusion behavior, morphology, and physical foam properties of organic cellulose ester. J. Mater. Res. 28, 2394 (2013).

27. T.M. Keaveny, E.F. Morgan, G.L. Niebur, and O.C. Yeh: Biomechanics of trabecular bone. Annu. Rev. Biomed. Eng. 3, 307 (2001).

28. D. Boettge, G. Standke, A. Fuessel, and J. Adler: Functionalization of open-celled foams by homogeneous slurry based coatings. J. Mater. Res. 28, 2220 (2013).

29. J. Richardson, Y. Peng, and D. Remue: Properties of ceramic foam catalyst supports: Pressure drop. Appl. Catal., A 204, 19 (2000).

30. F.C. Buciuman and B. Kraushaar-Czarnetzki: Ceramic foam monoliths as catalyst carriers. 1. Adjustment and description of the morphology. Ind. Eng. Chem. Res. 42, 1863 (2003).

31. P.G. Dixon and L.J. Gibson: The structure and mechanics of Moso bamboo material. J. R. Soc., Interface 11, 20140321 (2014)

32. J.F. Song, S.C. Xu, H.X. Wang, X.Q. Wu, and M. Zou: Bionic design and multi-objective optimization for variable wall thickness tube inspired bamboo structures. Thin-Walled Struct. 125, 76 (2018).

33. D. Hu, B. Song, L. Dang, and Z. Zhang: Effect of strain rate on mechanical properties of the bamboo material under quasistatic and dynamic loading condition. Compos. Struct. 200, 635 (2018).

34. W. Kindlein Júnior and A.S. Guanabara: Methodology for product design based on the study of bionics. Mater. Des. 26, 149 (2005).

35. M. Zou, S. Xu, C. Wei, H. Wang, and Z. Liu: A bionic method for the crashworthiness design of thin-walled structures inspired by bamboo. Thin-Walled Struct. 101, 222 (2016).

36. S. Liu, Z. Tong, Z. Tang, Y. Liu, and Z. Zhang: Bionic design modification of non-convex multi-corner thin-walled columns for improving energy absorption through adding bulkheads. ThinWalled Struct. 88, 70 (2015).

37. Z. Shao and F. Wang: The Fracture Mechanics of Plant Materials (Springer Singapore, Singapore, 2018); pp. 125-146.

38. D. Taylor, B. Kinane, C. Sweeney, D. Sweetnam, P. O'Reilly, and K. Duan: The biomechanics of bamboo: Investigating the role of the nodes. Wood Sci. Technol. 49, 345 (2015).

39. W. Liese and T.K.H. Tang: Properties of the Bamboo Culm, in Bamboo Plant Its Uses, W. Liese and M. Köhl, eds. (Springer, Cham, Berlin, 2015); pp. 227-256.
40. Y. Ding and W. Liese: Anatomical Investigations on the Nodes of Bamboos, in The Bamboos, L. Soc and G. Chapman, eds. (Academic Press, London, 1997); pp. 265-279.

41. T. Haushahn, T. Speck, and T. Masselter: Branching morphology of decapitated arborescent monocotyledons with secondary growth. Am. J. Bot. 101, 754 (2014).

42. P. Huang, W-S. Chang, M.P. Ansell, Y.M.J. Chew, and A. Shea: Density distribution profile for internodes and nodes of Phyllostachys edulis (Moso bamboo) by computer tomography scanning. Constr. Build. Mater. 93, 197 (2015)

43. G. Peng, Z. Jiang, X. Liu, B. Fei, S. Yang, D. Qin, H. Ren, Y. Yu, and H. Xie: Detection of complex vascular system in bamboo node by X-ray $\mu \mathrm{CT}$ imaging technique. Holzforschung 68, $223(2014)$.

44. C.R. Brodersen and A.B. Roddy: New frontiers in the threedimensional visualization of plant structure and function. Am. J. Bot. 103, 184 (2016).

45. F.M. Nogueira, S.A. Kuhn, F.L. Palombini, G.H. Rua, A. C. Andrello, C.R. Appoloni, and J.E.A. Mariath: Tankinflorescence in nidularium innocentii (Bromeliaceae): Threedimensional model and development. Bot. J. Linn. Soc. 185, 413 (2017).

46. F.L. Palombini, W. Kindlein Júnior, F.P. Silva, and J.E. de Araujo Mariath: Design, biônica e novos paradigmas: Uso de tecnologias 3D para análise e caracterização aplicadas em anatomia vegetal. Des. Tecnol. 7, 46 (2017).

47. F. Rengier, A. Mehndiratta, $H$. von Tengg-Kobligk, C. M. Zechmann, R. Unterhinninghofen, H-U. Kauczor, and F. L. Giesel: 3D printing based on imaging data: Review of medical applications. Int. J. Comput. Assist. Radiol. Surg. 5, 335 (2010).

48. E. Maire, A. Fazekas, L. Salvo, R. Dendievel, S. Youssef, P. Cloetens, and J.M. Letang: X-ray tomography applied to the characterization of cellular materials. Related finite element modeling problems. Compos. Sci. Technol. 63, 2431 (2003).

49. C. Petit, S. Meille, and E. Maire: Cellular solids studied by X-ray tomography and finite element modeling-A review. J. Mater. Res. 28, 2191 (2013)

50. X. Xiong, S.Z. Shen, L. Hua, J.Z. Liu, X. Li, X. Wan, and M. Miao: Finite element models of natural fibers and their composites: A review. J. Reinf. Plast. Compos. 37, 617-635 (2018).

51. E.C.N. Silva, M.C. Walters, and G.H. Paulino: Modeling bamboo as a functionally graded material: Lessons for the analysis of affordable materials. J. Mater. Sci. 41, 6991 (2006).

52. N. Naouar, E. Vidal-Salle, J. Schneider, E. Maire, and P. Boisse 3D composite reinforcement meso F.E. analyses based on X-ray computed tomography. Compos. Struct. 132, 1094 (2015).

53. J.J.A. Janssen: Designing and Building with Bamboo (International Network for Bamboo and Rattan, China, 2000).

54. S. Bolte and F.P. Cordelières: A guided tour into subcellular colocalization analysis in light microscopy. J. Microsc. 224(Pt 3), 213 (2006). 
55. P.H. Raven, R.F. Evert, and S.E. Eichhorn: Raven Biology of Plants, 8th ed. (W. H. Freeman, New York, 2013).

56. A. Colli, A.M. do Nascimento, L.M. Xavier, I.B. Rubim, A. Colli, A.M. do Nascimento, L.M. Xavier, and I.B. Rubim: Physical and mechanical properties and preservation, with boron and tannin, of the Bambusa tuldoides (Munro). Braz. J. Environ. 14, 56 (2007).

57. A.M. Nascimento, S.F. Stachera, and L.M. Xavier: Determinação de algumas propriedades físicas e mecânicas do Bambusa tuldoides (Munro). II Congr. Ibero-Americano Pesqui. e Desenvolv. Prod. Florestais (Curitiba, 2002); p. 17.

58. P.P.H. But and L.C. Chia: Bambusa tuldoides Munro, in Plant Resources South-East Asia No. 7 Bamboos, S. Dransfield and E. A. Widjaja, eds. (Backhuys Publishers, Leiden (Netherlands), 1997); pp. 72-74.

59. J.J.A. Janssen: Mechanical Properties of Bamboo (Springer Netherlands, Dordrecht, 1991).

60. R.A. Kerstetter: Shoot meristem formation in vegetative development. Plant Cell 9, 1001 (1997).

61. A. Mortensen, ed.: Concise Encyclopedia of Composite Materials, 2nd ed. (Elsevier, Amsterdan, 2007).

62. S.K. Boyd: Advanced Imaging in Biology and Medicine (Springer Berlin Heidelberg, Berlin, Heidelberg, 2009); pp. 301-318.

63. D. Ohrnberger: The Bamboos of the World: Annotated Nomenclature and Literature of the Species and the Higher and Lower Taxa (Elsevier Science B.V., Amsterdan, 1999).
64. D.A. Johansen: Plant Microtechnique (McGraw-Hill Book, New York, 1940).

65. D.S. Sampaio, M.C. de Chiara Moço, and J.E.A. Mariath: Floral ontogeny of Aeschynomene falcata and A. sensitiva (Leguminosae: Papilionoideae) supports molecular phylogenetic data. Plant Systemat. Evol. 299, 499 (2013).

66. E.N. Landis and D.T. Keane: X-ray microtomography. Mater. Charact. 61, 1305 (2010).

67. M.K. Cidade, F.L. Palombini, L. da Cunha Duarte, and S. Paciornik: Investigation of the thermal microstructural effects of $\mathrm{CO}_{2}$ laser engraving on agate via X-ray microtomography. Opt. Laser Technol. 104, 56 (2018).

68. S.R. Stock: MicroComputed Tomography: Methodology and Applications (CRC Press, Boca Raton, Florida, 2009).

69. J. Schindelin, I. Arganda-Carreras, E. Frise, V. Kaynig, M. Longair, T. Pietzsch, S. Preibisch, C. Rueden, S. Saalfeld, B. Schmid, J-Y. Tinevez, D.J. White, V. Hartenstein, K. Eliceiri, P. Tomancak, and A. Cardona: Fiji: An open-source platform for biological-image analysis. Nat. Methods 9, 676 (2012)

70. A. Buades, B. Coll, and J-M. Morel: Non-local means denoising. Image Process. Line 1, 208 (2011).

71. C. Geuzaine and J-F. Remacle: Gmsh: A 3-D finite element mesh generator with built-in pre- and post-processing facilities. Int. J. Numer. Methods Eng. 79, 1309 (2009). 